\title{
Recurrent Hypoglycemia in Diabetic Patient With Hypopituitarism: The Houssay Phenomenon
}

\author{
Mohammed Gaffar Mohammed ${ }^{1}$, Javeria Baloch ${ }^{2}$, Ahmed M. Alsahhar ${ }^{3}$, Budur M. Alhabashi ${ }^{1}$ \\ 1. Internal Medicine, Dr. Sulaiman Al Habib Hospital, Riyadh, SAU 2. Internal Medicine, College of Medicine, Alfaisal \\ University, Riyadh, SAU 3. Internal Medicine/General, Sulaiman Alrajhi University, Al Bukairiyah, SAU
}

Corresponding author: Mohammed Gaffar Mohammed, mgama2001@hotmail.com

\begin{abstract}
The association of treatment of diabetes mellitus and hypoglycemia is well described in the literature. However, the association of recurrent hypoglycemia in diabetic patients with hypopituitarism has been rarely described. This phenomenon, called Houssay phenomenon, usually occurs in individuals with a long diabetes evolution. It is caused by the failure of counter-regulatory hormones produced by the anterior pituitary gland to correct hypoglycemia. We describe this phenomenon in an elderly female known with type 2 diabetes mellitus taking insulin and oral diabetes medications. Workup showed partially empty sella on pituitary imaging. Hormonal assessment showed very low morning cortisol, low adrenocorticotropin hormone (ACTH) and zero response to synacthen. Loss of these counter-regulatory hormones leads to hypoglycemia (Houssay phenomenon). Hypopituitarism has several causes, including pituitary adenoma and traumatic brain injury as common causes among the others. In our reported case, we correlate our patient's condition to Houssay phenomenon, for the implication of refractory hypoglycemic episodes and cortisol deficiency, all of which are the consequences of hypopituitarism. Clinicians should be aware of the link between diabetes and hypopituitarism to avoid deleterious consequences of hypoglycemia.
\end{abstract}

Review began 02/09/2021 Review ended 02/14/2021 Published 02/18/2021

๑) Copyright 2021 Gaffar Mohammed et al. This is an open access article distributed under the terms of the Creative Commons Attribution License CC-BY 4.0., which permits unrestricted use, distribution, and reproduction in any medium, provided the original author and source are credited.
Categories: Endocrinology/Diabetes/Metabolism, Internal Medicine, Neurology

Keywords: hypoglycemia, houssay phenomenon, hypopituitarism, recurrent hypoglycemia, partial empty sella turcica, short synthacten test, low cortisol, hypocotisolism

\section{Introduction}

Patients with type 2 diabetes who are taking medications, such as insulin or sulfonylureas, are prone to develop hypoglycemia. However, a rare yet important cause of severe hypoglycemia is pituitary dysfunction in diabetic patients known as the Houssay phenomenon. Anterior pituitary dysfunction leads to loss of function of counter-regulatory hormones, which leads to increased insulin sensitivity causing hypoglycemia and sometimes resolution of diabetes [1]. We report a case of severe recurrent hypoglycemia in a 64-yearold female on insulin, sitagliptin, gliclazide and metformin for type 2 diabetes, secondary to hypopituitarism. She developed recurrent episodes of hypoglycemia and loss of consciousness despite discontinuation of insulin and oral hypoglycemic medication. Furthermore, brain imaging revealed a partially empty sella along with a poor Synthacten test response, low cortisol and low adrenocorticotropin hormone (ACTH) levels.

\section{Case Presentation}

A 64-year-old female was brought into the emergency department following an episode of loss of consciousness, which was associated with hypoglycemic symptoms of sweating, shivering and dizziness. The random blood sugar level on presentation to the emergency room was $40 \mathrm{mg} / \mathrm{dL}$ (2.2 $\mathrm{mmol} / \mathrm{L})$. She was given intravenous dextrose infusion to regain consciousness.

She has diabetes for 15 years. She had been on insulin and oral diabetes medications. Her heamoglobin A1c (HbA1c) was $11.7 \%$ (104 mmol/mol) three months prior to presentation to the emergency room.

However, her HbA1c was reduced to $6.5 \%$ (38 mmol $/ \mathrm{mol}$ ) upon her admission with hypoglycemia. Her blood glucose levels remained low despite discontinuation of diabetic treatment. Frequent $10 \%$ dextrose infusions were required. Nonetheless and even with close monitoring, she further developed hypoglycemic episodes requiring ICU admission. While in ICU, she developed generalized tonic-clonic seizures. Following this, a brain MRI was done, which revealed nothing significant except a partially empty sella turcica (Figure 1). 


\section{Cureus}

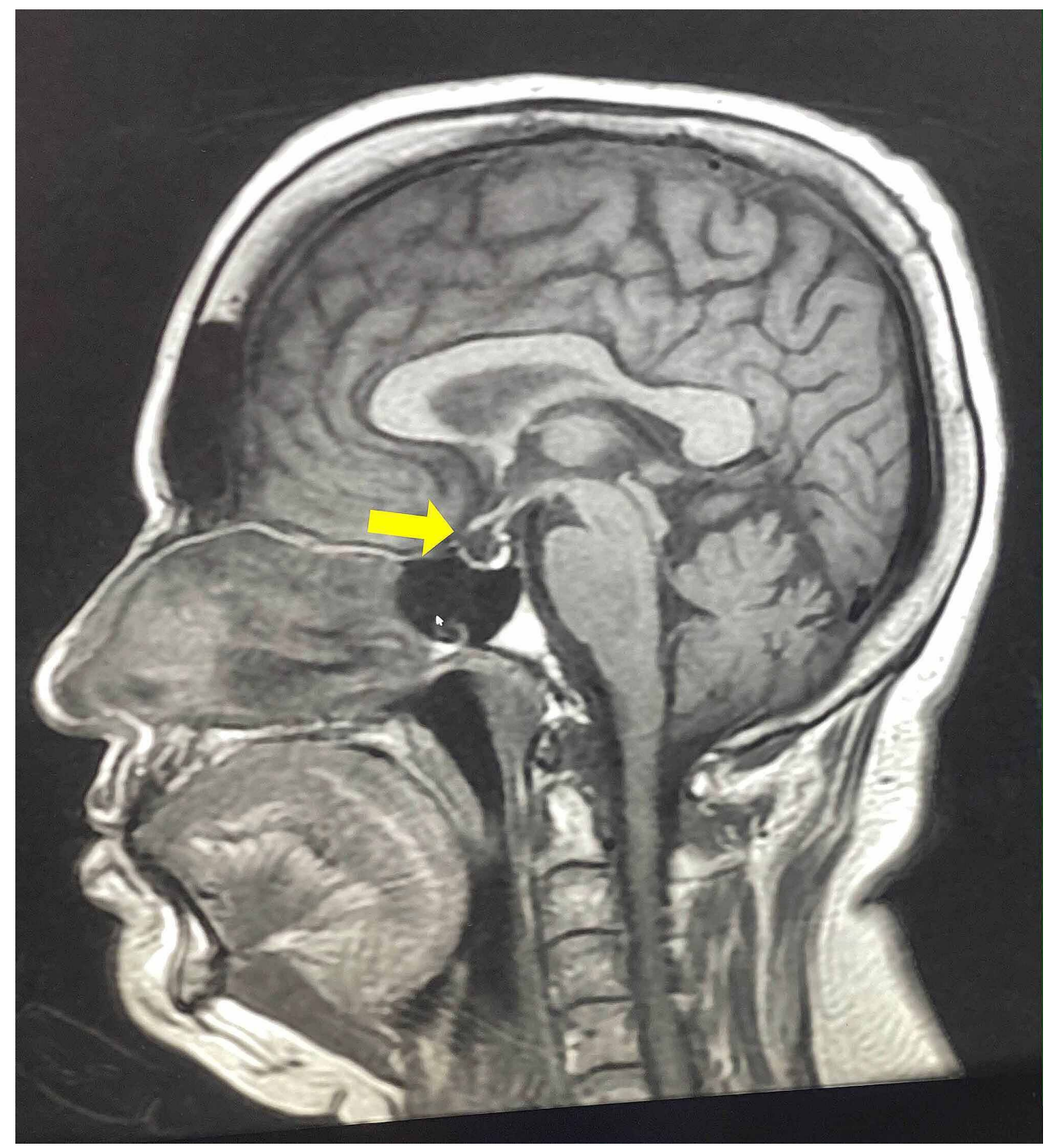

FIGURE 1: Sagittal MRI view of the hypothalamopituitary showing partially empty sella (yellow arrow)

Her initial hormone workup revealed low cortisol, low follicular stimulating hormone (FSH), low luteinizing hormone (LH), low somatomedin level and low ACTH levels with normal thyroid-stimulating hormone (TSH), normal aldosterone, normal renin, normal aldosterone/renin ratio and normal prolactin. She had low morning cortisol of $25 \mathrm{nmol} / \mathrm{L}$ and low ACTH of $0.44 \mathrm{pmol} / \mathrm{L}$. Further assessment showed poor response to short Synthacten test with cortisol levels of 24.7, 95.8 and $130.5 \mathrm{nmol} / \mathrm{L}$ at 0, 30 and 60 minutes, respectively (summarized in Table 1). 


\section{Cureus}

\begin{tabular}{|c|c|c|}
\hline Test & Patient result & References \\
\hline Haemoglobin (g/dL) & $13.8 \mathrm{~g} / \mathrm{dL}$ & $11.8-14.8 \mathrm{~g} / \mathrm{dL}$ \\
\hline HBA1C (\%) & $6.4 \%$ & $<5.7 \%$ \\
\hline $\mathrm{Na}(\mathrm{mEq} / \mathrm{L})$ & $126 \mathrm{mEq} / \mathrm{L}$ & 136-145 mEq/L \\
\hline 8am serum cortisol (nmol/L) & $25.60 \mathrm{nmol} / \mathrm{L}$ & $101.2-535.7 \mathrm{nmol} / \mathrm{L}$ \\
\hline 8 pm serum cortisol (nmol/L) & $8 \mathrm{nmol} / \mathrm{L}$ & 79-477 nmol/L \\
\hline RBS (mg) & $40 \mathrm{mg}$ & $70-140 \mathrm{mg}$ \\
\hline $\mathrm{TSH}(\mathrm{mlu} / \mathrm{mL})$ & $1.29 \mathrm{mlU} / \mathrm{mL}$ & $0.3-4.2 \mathrm{mlU} / \mathrm{mL}$ \\
\hline Somatomedin C (IGF-1) (ng/mL) & $10.6 \mathrm{ng} / \mathrm{mL}$ & $42.2-169 \mathrm{ng} / \mathrm{mL}$ \\
\hline $\begin{array}{l}\text { Cortisol after short Synthacten test } \\
\text { (nmol/L) }\end{array}$ & $\begin{array}{l}0 \mathrm{~min}: 24.7 \mathrm{nmol} / \mathrm{L} 30 \mathrm{~min}: 95.8 \mathrm{nmol} / \mathrm{L} 60 \mathrm{~min}: \\
130.5 \mathrm{nmol} / \mathrm{L}\end{array}$ & $\begin{array}{l}\text { Normal response }>420 \mathrm{nmol} / \mathrm{L} \text { at } 30 \\
\min \end{array}$ \\
\hline $\mathrm{FSH}(\mathrm{mlU} / \mathrm{m})$ & $4.83 \mathrm{mlU} / \mathrm{m}$ & $\begin{array}{l}\text { 25.8-134.8 } \mathrm{mlU} / \mathrm{m} \text { (Post-menopausal } \\
\text { range) }\end{array}$ \\
\hline $\mathrm{LH}(\mathrm{m} \mathrm{lU} / \mathrm{m})$ & $2.86 \mathrm{mlU} / \mathrm{m}$ & $\begin{array}{l}7.7-58.5 \mathrm{mlU} / \mathrm{m} \text { (Post-menopausal } \\
\text { range) }\end{array}$ \\
\hline Prolactin (mg/dL) & $276 \mathrm{mg} / \mathrm{dL}$ & $102-496 \mathrm{mg} / \mathrm{dL}$ \\
\hline ACTH (pmol/L) & $0.44 \mathrm{pmol} / \mathrm{L}$ & 1.1-13.2 pmol/L \\
\hline Aldosterone (ng/dL) & $13.2 \mathrm{ng} / \mathrm{dL}$ & $3.7-43 \mathrm{ng} / \mathrm{dL}$ \\
\hline Renin (mU/mL) & $29.7 \mathrm{mU} / \mathrm{mL}$ & $5.3-99 \mathrm{mU} / \mathrm{mL}$ \\
\hline
\end{tabular}

\section{TABLE 1: Laboratory results}

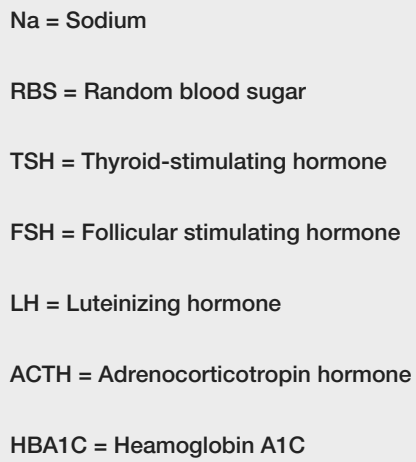

The patient was diagnosed with primary pituitary failure with secondary adrenal insufficiency considering the investigation results. She was started on IV hydrocortisone followed by oral hydrocortisone $10 \mathrm{mg}$ twice daily and was discharged on the same dose of hydrocortisone, in addition to oral hypoglycemic medications (linagliptin, empagliflozin and metformin). Since then, no more episodes of hypoglycemia have been reported and she remained stable over the remaining course of her hospital stay. Upon her follow-up visits in the outpatient clinic for the last five months, she reported improvement in her symptoms with no further hypoglycemic episodes with well-controlled self-home blood glucose monitoring.

\section{Discussion}

Unexplained hypoglycemia in a diabetic patient should alert vigilant searches for deficiency in counterregulatory hormones, particularly, pituitary and adrenal hormones. Development of hypoglycemia in a diabetic patient is a major health challenge to the physician and the patient owing to the fact that hypoglycemia has dangerous consequences to the patient. The occurrence of hypoglycemia in a diabetic individual can be due to different causes, including iatrogenic hypoglycemia by insulin, or oral hypoglycemic agents, in particular sulfonylurea. Moreover, diabetic patients on treatment are at risk of hypoglycemia 
under starvation and physical exhaustion. Other causes are renal impairment, liver disease, cardiac failure, sepsis as well as alcohol [2].

There is an array of hormones that act as counter-regulatory measures against falling blood glucose levels, particularly glucagon, adrenaline, cortisol and growth hormone. Inadequacy of these hormones may lead to hypoglycemia. One reason for inadequacy is anterior hypopituitarism, a condition in which the pituitary gland is unable to produce its hormones. The most common causes giving rise to the condition are nonfunctioning pituitary adenomas, traumatic brain injury and congenital defects. Other causes include hypothalamic diseases, ischemic disease and infections [3-4]. The decline of hormone production in the course of hypopituitarism is sequential; with growth hormone and gonadotropin hormones being affected first, followed by ACTH and TSH. Prolactin is rarely decreased; however, in Sheehan's syndrome, it is substantially decreased [4]. Insufficient ACTH hormone secretion results in cortisol deficiency; therefore, hypopituitarism may cause hypoglycemic events in diabetic patients on medical treatment including insulin therapy. Furthermore, recurrent episodes of hypoglycaemia impair the glucose counter-regulatory mechanisms, predisposing to severe hypoglycaemia [5]. Notably, cortisol deficiency is associated with a lack of aldosterone like effect of cortisol on the kidneys level resulting in hyponatremia, as well as antidiuretic hormone $(\mathrm{ADH})$ release is affected negatively by cortisol secretion.

Thus, the manifestation of unexplained hyponatremia in hypoglycemic diabetic individuals suggests the possibility of hypocortisolism and hypopituitarism [6]. Interestingly, hypopituitarism is considered an uncommon cause for hypoglycemia in diabetics. However, there are a fair number of case reports representing the condition.

A phenomenon, named Houssay phenomenon, has described the possibility of recurrent hypoglycemic events in a diabetic patient due to hypopituitarism. The phenomenon was named after Bernardo Houssay, for his experiments in 1931 and his explanation of amelioration of diabetes in dogs that had undergone pancreatectomy following the loss of counter-regulatory hormones by removal of anterior pituitary gland [7]. Fewer cases reported duplication of this phenomenon in the following years after its discovery. One of the first reported cases in a human was described by Lyall and Innes in 1935 [8]. A diabetic patient who suffered from hypoglycemic events due to hypopituitarism followed by spontaneous remission to diabetes and his glucose tolerance considerably improved [8].

We correlate this phenomenon to our reported case. Our patient suffered from type 2 diabetes for 15 years. Her sugar levels were not well controlled as evident by her HbA1c done three months prior to her admission to the emergency room. Then, the patient developed recurrent episodes of hypoglycemia despite discontinuation of the insulin and administration of dextrose. Our diagnosis of Houssay phenomenon is supported by low ACTH, low basal cortisol, failure of cortisol response to synacthen and low IGF1. Classically, TSH is reduced concomitantly with ACTH in the state of hypopituitarism, but in our case, TSH appeared to be normal. Furthermore, our patient's condition improved significantly following treatment with no further reports of recurrent documented or symptomatic hypoglycemia for the last five months, which supports our decision and confirms our diagnosis further.

\section{Conclusions}

Unlike the common causes of hypoglycemia, such as overdosing with insulin or oral hypoglycemic, starvation and increased activity, hypopituitarism is a rare but a serious cause of hypoglycemia that needs to be addressed urgently. Physicians should be conscious about the possibility of hypoglycemia in the setting of anterior pituitary dysfunction in cases presenting with repeated episodes of hypoglycemia. Moreover, the recurrent episodes may lead to even more severe episodes with time, placing the patient in a lifethreatening condition. This can be avoided by early recognition of the condition and prompt delivery of the appropriate treatment.

\section{Additional Information \\ Disclosures}

Human subjects: Consent was obtained or waived by all participants in this study. Conflicts of interest: In compliance with the ICMJE uniform disclosure form, all authors declare the following: Payment/services info: All authors have declared that no financial support was received from any organization for the submitted work. Financial relationships: All authors have declared that they have no financial relationships at present or within the previous three years with any organizations that might have an interest in the submitted work. Other relationships: All authors have declared that there are no other relationships or activities that could appear to have influenced the submitted work.

\section{References}

1. Pramanik S, Bhattacharjee R, Mukhopadhyay P, Ghosh S: Lesson of the month 2: Houssay phenomenon hypopituitarism leading to remission of diabetes. Clin Med (Lond). 2016, 16:294-296.

10.7861/clinmedicine.16-3-294

2. Cryer PE, Axelrod L, Grossman AB: Evaluation and management of adult hypoglycemic disorders: an 


\section{Cureus}

Endocrine Society Clinical Practice Guideline. J Clin Endocrinol Metab. 2009, 94:709-728. 10.1210/jc.20081410

3. van Aken MO, Lamberts SW: Diagnosis and treatment of hypopituitarism: an update. Pituitary. 2005, 8:183191.

4. Chung TT, Koch CA, Monson JP: Hypopituitarism. Feingold KR, Anawalt B, Boyce A, et al., (ed): MDText.com, Inc., South Dartmouth, MA; 2000.

5. Cryer PE: Defining and reporting hypoglycemia in diabetes: A report from the american diabetes association workgroup on hypoglycemia. Diabetes Care. 2005, 28:1245-1249.

6. Samaan NA: Hypoglycemia secondary to endocrine deficiencies. Endocrinol Metab Clin North Am. 1989, 18:145-154.

7. Hadithi M, Toorians A, Heine R: The Houssay phenomenon, another clue to Sheehan's syndrome in a diabetic. Diabet Med. 2002, 19:795.

8. Lyall A, Innes JA: Diabetes mellitus and the pituitary gland: a case of diabetes with intercurrent pituitary lesion and concomitant improvement of diabetes. The Lancet. 1935, 225:318-321. 